\title{
Üniversite Öğrencilerinde Ayak Medial Longitudinal Ark Durumunun Denge ve Esneklikle İlişkisi
}

\author{
Selin Akılø, Serpil Çolak®
}

İstanbul Medipol Üniversitesi, Fizyoterapi ve Rehabilitasyon, İstanbul, Türkiye

Selin Akıl, Uzm. Fzt.

Serpil Çolak, Dr. Öğr. Üyesi

Iletişim:

Uzm. Fzt. Selin Akıl

İstanbul Medipol Üniversitesi, Fizyoterapi ve Rehabilitasyon, İstanbul , Türkiye

Tel: +90 5366446915

E-Posta: fztselinakil@gmail.com
Gönderilme Tarihi : 02 Nisan 2019

Revizyon Tarihi : 24 Haziran 2019

Kabul Tarihi

: 24 Temmuz 2019
ÖZET

Amaç: Bu çalışmanın amacı; üniversite öğrencilerinde ayak medial longitudinal ark yüksekliğinin denge ve esneklik üzerine etkisini değerlendirmektir.

Hastalar ve Yöntemler: Çalışmaya 18-30 yaş aralığında üniversitede öğrenim görmekte olan toplam 81 öğrenci dahil edildi. Olguların ayak medial longitudinal ark değerlendirmesi için Harris Mat kullanııdı. Bireyler, ayak izi değerlendirme sonucuna göre sırayla normal, yüksek ve düşük ark grubu olarak üçe ayrıldı. Gruplardaki katılımclara statik denge değerlendirmesi için tek ayak üstünde durma testi, dinamik denge değerlendirmesi için Star Excursion Balance Test uygulandı. Gastrokinemius ve hamstring kas esneklik ölçümleri için mezura kullanıldı. Grupların değerlendirme sonuçları karşılaştıııldı.

Bulgular: Gruplardaki katılımcıların 21'i kadın, 6'sı erkekti. Bulgulara bakıldığında, normal ark grubunda Star Excursion sol ayak üzerinde posteriora uzanma ve hamstring kas esnekliği sonuçları diğer gruplara göre istatistiksel açıdan anlamlı bulundu $(p<0,05)$. Gastrokinemius kas esnekliği ve statik denge değerlendirmesinde gruplar arasında anlamlı fark bulunmadi $(p>0,05)$.

Sonuç: Sonuç olarak normal ayak ark yüksekliğinin artmasının ve azalmasııın dinamik dengedeki bazı parametreleri ve hamstring kas esnekliğini olumsuz etkilediği, gastrokinemius kas esnekliği ve statik dengeyi etkilemediği görüldü. Ayak ark deformitesi olan bireylerde, denge ve kas esneklik etkilenimlerinin de göz önüne alınması gerektiği kanııına varıldı.

Anahtar sözcükler: Denge, düşük ark, esneklik, medial longitudinal ark, yüksek ark

THE RELATIONSHIP BETWEEN BALANCE AND FLEXIBILITY OF FOOT MEDIAL LONGITUDINAL ARCH STATUS IN UNIVERSITY STUDENTS

\section{ABSTRACT}

Objective: The aim of this study was to evaluate the status of the foot medial longitudinal arch height in university students and its effect on a person's muscle flexibility and balance.

Patients and Methods: This research was carried out on 81 students (ages ranging from 18 to 30 ) studying at university. The foot medial longitudinal arch height was evaluated with Harris Mat. Students were divided into three groups according to the evaluation of the footprint: Normal, high and low arch. The balance was assessed for all participants with Single-Leg Stance Test and Star Excursion Balance Test. Gastrocnemius and hamstring muscle flexibility were measured by a tape measure. Evaluation results of groups were compared.

Results: There were 27 people (21 females, 6 males) in all three groups. In the normal arch group, Star Excursion left posterior on the left foot and hamstring muscle flexibility results were found to be statistically higher than the other groups. $(p<0.05)$. There was no significant difference between the groups in the evaluation of gastrocnemius muscle flexibility and static balance parameters $(p>0.05)$.

Conclusion: As a result, it was seen that the increase and decrease of normal foot arch height negatively affected some parameters in dynamic balance and hamstring muscle flexibility and did not affect gastrocnemius muscle flexibility and static balance. It was concluded that balance and muscle flexibility effects should be considered in individuals with foot arch deformity.

Keywords: Balance, flexibility, high arch, low arch, medial longitudinal arch 
M edial longitudinal ark (MLA) yüksekliğinde değişimler sonucu görülen pes planus (PP) ve pes kavus (PK), ayakta yaygın görülen ark problemleridir. PP ile ilgili yapılan çalışmalar, ark değişikliğinin postür bozukluğu, kaslarda kısalık, total ayak kuvvetinde azalma ve çabuk yorulmaya sebep olduğunu ve dengeyi olumsuz yönde etkilediğini göstermektedir (1).

Denge, santral ve periferal sinir sistemlerinin birbirleriyle etkileşimi ile sağlanır. Dengenin sağlanması ve düzgün postür için somatosensoriyal, vizüel ve vestibular sistemleri içeren periferal komponentlerden santral sinir sistemine duyusal girdiler ulaşır ve santral sistem tarafından uygun kas stratejileri oluşturulur. (2).

Vücudun herhangi bir ekleminde oluşan bozukluk, zincir şeklinde tüm vücudu etkiler. Alt ekstremite incelendiğinde en distal yapı olan ayak ile zemin temasın sağlandığı görülmektedir. Bu sebeple ayakta oluşan biyomekanik değişiklikler postüral kontrol stratejileri ve dengeyi etkileyebilir. Özellikle subtalar eklemde aşıı pronasyon ve supinasyon, taban basıncında değişikliklere sebep olur, eklem hareketliliğini ve eklem etrafındaki kasları etkileyip somatosensoriyal girdiyi değiştirebilir. Bu sebeple hem PP hem de PK'da, taban temas yüzeyinde görülen etkilenim sebebi ile ayak tabanının zemine uyumu zorlaşacağından, denge ve stabilizasyon olumsuz etkilenebilir, eklem etrafında bulunan kasların iş yükü artabilir $(2,3)$.

Pes kavus ile ilişkili literatür incelendiğinde az sayıda çalışmaya rastlanmaktadır. PP ile ilgili literatürde fiziksel uygunluk parametrelerine yönelik çalışmalar vardır ancak genellikle denge, kas kuvveti gibi tek parametre üzerine yoğunlaşıldığı görülür, birden çok parametrenin incelendiği çalışmalarda ise çoğunlukla tek cinsiyet üzerinde değerlendirme yapılmıştır. Ayak arkında yükseklik değişiminin üniversite öğrencisi kadın ve erkeklerde statik denge, dinamik denge ve kas esnekliği üzerine etkisinin değerlendirildiği bir araştırmaya rastlanmamıştır.

Bu çalışmanın amacı üniversite öğrencilerinde MLA yüksekliğinin artması veya azalmasının, normal MLA yüksekliğine sahip bireylere göre statik denge, dinamik denge ve kas esnekliği üzerinde oluşturduğu etkileri araştırmaktır.

\section{Materyal ve Metot}

Çalışmaya 18-30 yaş aralığında üniversitede öğrenim görmekte olan 'Bilgilendirilmiş Gönüllü Olur Formu' nu okuyup kabul eden sağlıklı bireyler katıldı. Aktif spor yaşamına sahip olanlar, obez bireyler, ortopedik, kardiyopulmoner ve denge problemi olanlar çalışmadan dışlandı. Çalışmaya katılan olgular, araştırmacı tarafından hazırlanan 'Katılımcı Değerlendirme Formu' ile değerlendirildi. Bu formda ad, soyad, cinsiyet, boy, kilo, BKi (Beden Kütle İndeksi), ayakkabı numarası, dominant ekstremite, aktif spor geçmişi, alt ekstremite travma öyküsü, kardiyopulmoner, denge ve ortopedik problem varlığı sorgulandı.

Ayak arkının değerlendirilmesi için Harris Mat kullanıldı. Kişilerin ayak izini almak için kullanılan bu yöntemde, mürekkepli zemin rulo ile boyanıp, beyaz kâğıt araya konuldu ve tabaka kapatıldı. Kişilerin önce değerlendirme yapılmayan taraf ayağını mavi zemine basmaları, daha sonra diğer ayakla altında mürekkepli zemin bulunan tabakaya basmaları ve her iki ayağa eşit yük aktarmaları istendi ve değerlendirme her iki ayak için tekrarlandı. Beyaz kâğıttaki küçük kare şekilleri esas alınarak ayak izi değerlendirildi. MLA değerlendirmesi Staheli İndeksine uygun şekilde orta ayağın en dar kısmının, topuğun en geniş kısmına oranı ile bulundu. Oranın 0,7'den küçük olması yüksek ark, 0,7-1 arası normal ark, 1 ve 1'den fazla olması düşük ark olarak kabul edildi. Bu kriterlere uygun şekilde katılımcılar üç gruba ayrıldı. Sırasıyla normal ark, yüksek ark ve düşük ark olarak sınıflandırıldı (4-7).

Araştırmaya alınacak kişi sayısını belirlemek üzere güç (power) analizi yapıldı. Testin gücü, G*Power 3,1 programı ile hesaplandı. Çalışmanın gücünün belirlenmesinde $\% 95$ değerini geçmesi için; \%5 anlamlılık düzeyinde ve 0,450 etki büyüklüğünde gruplarda 27 kişi olmak üzere 81 katılımcıya ulaşılması gerektiği saptandı. Çalışmada gruplara güç analizine uygun şekilde 21 kadın, 6 erkek birey alındı.

Statik denge değerlendirmesinde kullanılan tek ayak üstünde durma testinde katılımcılar, bacakları birbirine temas etmeyecek şekilde tek ayak üzerinde durdu. Katılımcıların sağ ve sol ayak üzerinde pozisyonu koruyabildiği süre saniye cinsinden kaydedildi. Katılımcılar 120 sn. pozisyonu koruyabildiklerinde süre durduruldu. Aynı uygulama gözler kapalı şekilde tekrarlandı. İki bacak arasında temas olduğunda, kaldırılan taraf ayak yere temas ettiğinde, destek için bir yere dokunulduğunda ya da sekme olduğunda test sonlandırıldı (8).

Star Excursion Balance Test için katılımcıdan $45^{\circ}$ açılarla A (anterior), AM (anteromedial), M (medial), PM (posteromedial), P (posterior), PL (posterolateral), L (lateral) ve AL (anterolateral) yönlerde yıldız şeklindeki bir düzeneğin merkezinde değerlendirme yapılan taraf ayak üzerinde durması istendi. Katılımcı sırasıyla değerlendirme yapılmayan ayağı ile $A M, M, P M, P, P L, L, A L$ ve $A$ yönlere uzandı. Katılımcının maksimum uzandığı mesafe santimetre 
cinsinden kaydedildi ve değerlendirme her iki ayak için de tekrarlandı $(9,10)$.

Gastrokinemius kas esnekliğinin bilateral değerlendirilmesinde; başlama pozisyonu olarak katılımcıdan duvardan $1 \mathrm{~m}$ uzaklıkta, elleri ile duvara dayanarak ayakta durması istendi. Katılımcı dirsek fleksiyonu gövdesini öne alırken, klavikular çentiğin duvara uzaklığı mezura ile santimetre cinsinden kaydedildi. Test sırasında kişinin sırt ve gövdesinin düz olmasına ve topuklarının yerden kalkmamasına dikkat edildi (11).

Hamstring kas esnekliği bilateral değerlendirmesinde, kişiden bir basamak üzerinde, dizleri ekstansiyonda iken öne doğru eğilerek parmak ucuna dokunmaya çalışması istendi. Parmak ucu ile basamak arasındaki uzaklık mezura ile ölçüldü Basamak yüzeyinin altındaki değerler pozitif, üstündeki değerler ise negatif olarak santimetre cinsinden kaydedildi (11).

$\mathrm{Bu}$ araştırmada elde edilen veriler SPSS (Statistical Package for Social Sciences) for Windows 22.0 programı kullanılarak analiz edildi. Verilerin değerlendirilmesinde tanımlayıcı istatistiksel yöntemleri olarak sayı, yüzde, ortalama, standart sapma kullanıldı.
İki bağımsız grup arasında niceliksel sürekli verilerin karşılaştırılmasında t-testi, ikiden fazla bağımsız grup arasında niceliksel sürekli verilerin karşılaştırılmasında Tek yönlü (Oneway) Anova testi kullanıldı. Anova testi sonrasında farklılıkları belirlemek üzere tamamlayıcı post-hoc analizi olarak Scheffe testi kullanıldı. Araştırmanın sürekli değişkenleri arasında korelasyon analizi uygulandı. Çalışmada anlamlılık düzeyi $\mathrm{p}<0,05$ olarak kabul edildi.

\section{Bulgular}

Katılımcıların demografik verileri Tablo 1'de gösterilmiştir. Normal, yüksek ve düşük ark grupları arasında yaş, boy ve kilo ortalamaları bakımından anlamlı olarak bir fark saptanmamıştır ( $p>0,05)$. Düşük ark grubunda, BKI sonuçları istatistiksel olarak anlamlı yüksek bulunmuştur $(p<0,05)$.

Olguların cinsiyete göre dağılımına bakıldığında gruplar arasında istatistiksel olarak anlamlı fark bulunmamıştır (Tablo 2) ( $p>0,05)$.

Grupların statik denge değerlendirme ortalamalarının karşılaştırılması Tablo 3'te gösterilmiştir. Gruplar arasında statik denge değerlendirme sonuçlarında anlamlı farklııı saptanmamıştır $(p>0,05)$.

\section{Tablo 1. Grupların demografik özelliklerinin karşılaştıııması}

\begin{tabular}{lcccc} 
& Normal Ark & Yüksek Ark & Düşük Ark & F/p \\
\hline & Ort. \pm SS & Ort. \pm SS & Ort. \pm SS & \\
\hline Yaş (yll) & $21,852 \pm 2,143$ & $21,000 \pm 1,961$ & $21,444 \pm 1,672$ & $1,309 / 0,276^{\mathrm{a}}$ \\
Boy (cm) & $1,689 \pm 0,097$ & $1,672 \pm 0,089$ & $1,662 \pm 0,090$ & $0,600 / 0,551^{\mathrm{a}}$ \\
Kilo $(\mathrm{kg})$ & $63,963 \pm 11,782$ & $60,148 \pm 10,978$ & $65,667 \pm 12,616$ & $1,546 / 0,220^{\mathrm{a}}$ \\
BKi $\left(\mathrm{kg} / \mathrm{m}^{2}\right)$ & $22,339 \pm 2,986$ & $21,448 \pm 2,939$ & $23,668 \pm 3,264$ & $3,581 / 0,033 \mathrm{a}^{\star}$ \\
\hline
\end{tabular}

a, ANOVA testi; *, $p<0,05 ;{ }^{* *}, p<0,001 ;$ Ort, ortalama; SS, standart sapma; BKi, vücut kütle indeksi.

Tablo 2. Olguların cinsiyetlerine göre gruplarda dağııımı

\begin{tabular}{ccccccccc} 
& & \multicolumn{2}{c}{ Normal Ark } & \multicolumn{2}{c}{ Yüksek Ark } & \multicolumn{2}{c}{ Düşük Ark } & \multicolumn{1}{c}{$\boldsymbol{p}$} \\
\hline & & $\boldsymbol{n}$ & $\%$ & $\boldsymbol{n}$ & $\%$ & $\boldsymbol{n}$ & $\%$ \\
\hline \multirow{2}{*}{ Cinsiyet } & Erkek & 6 & $\% 22,2$ & 7 & $\% 25,9$ & 7 & $\% 25,9$ & X2 $=0,133 \mathrm{~b}$ \\
& Kadın & 21 & $\% 77,8$ & 20 & $\% 74,1$ & 20 & $\% 74,1$ & $\mathrm{p}=0,936$ \\
\hline
\end{tabular}

b, ki-kare analizi, * $p<0,05 ;{ }^{* *}, p<0,001 ; n$, kişi sayısı.

Tablo 3. Grupların statik denge değerlendirme sonuçlarının ortalamaları

\begin{tabular}{lcccc} 
& Normal Ark & Yüksek Ark & Düşük Ark & F/p \\
\hline Sağ GA & Ort. \pm SS & Ort. \pm SS & Ort. \pm SS & \\
Sol GA & $116,333 \pm 13,528$ & $109,741 \pm 25,455$ & $108,593 \pm 29,977$ & $0,817 / 0,445 a$ \\
Sağ GK & $113,593 \pm 18,502$ & $104,444 \pm 30,456$ & $111,296 \pm 22,082$ & $1,044 / 0,357 a$ \\
Sol GK & $48,926 \pm 36,369$ & $36,333 \pm 29,404$ & $43,667 \pm 39,303$ & $0,868 / 0,424 a$ \\
\end{tabular}

a, ANOVA testi; *, $p<0,05 ;{ }^{* *}, p<0,001$; Ort, ortalama; SS, standart sapma; GA, gözler açık; GK, gözler kapalı. 
Grupların dinamik denge test ölçümlerinin ortalamaları Tablo 4'te gösterilmiştir. Bireylerin sağ ve sol A, AM, M, PM, $P L$, $L$ ve $A L$ puanları ark değişkenine göre anlamlı farklılık göstermemiştir ( $p>0,05)$. Arka göre sol ayak $P$ uzanma sonucu anlamlı farklılık göstermiştir $(p=0,037<0,05)$.

Grupların hamstring ve gastrokinemius kas esneklik değerlerinin ortalamaları Tablo 5'te gösterilmiştir. Ark durumuna göre hamstring kas esneklik sonuçları anlamlı farklılık gösterirken ( $F=4,275 ; p=0,017<0,05)$, gastrokinemius kas esneklik sonuçları anlamlı farklılık göstermemiştir $(p>0,05)$.

\section{Tartışma}

PP ve PK ayakta sık görülen deformitelerdir. MLA'nın durumu ile ilişkilendirilen bu deformiteler alt ekstremite kinetik zinciri aracılığıyla tüm vücut biyomekaniğini etkiler. Çalışmamızda üniversite öğrencilerinde ayak MLA durumunun denge ve esneklik üzerine etkisini değerlendirmeyi amaçladık.

Ayak, alt ekstremitenin en distalinde bulunan yapıdır ve zemine destek yüzeyi oluşturduğu için kişilerin dengeleri ile ilişkilendirilmiştir. Bu çalışmada dinamik denge değerlendirmesinde diğer gruplara kıyasla normal ark grubunda posteriora uzanma miktarı anlamlı olarak yüksek bulundu.

Literatürde de ayak arklarında görülen deformitelerin denge ve esnekliği olumsuz etkilediği rapor edilmiştir. El Shamy ve ark. adölesan grup kadınlarda PP'nin postural stabilite ile ilişkisini incelemiştir Çalışma 15-18 yaş

Tablo 4. Grupların dinamik denge sonuçlarııın karşılaşı̆ıııması

\begin{tabular}{|c|c|c|c|c|c|}
\hline & Normal Ark & Yüksek Ark & Düşük Ark & & \\
\hline & $O r t \pm S S$ & $O r t \pm S S$ & $O r t \pm S S$ & $F / p$ & Fark \\
\hline Sağ A & $76,741 \pm 10,512$ & $72,222 \pm 7,963$ & $74,963 \pm 7,925$ & $1,773 / 0,177 a$ & \\
\hline Sağ AM & $69,963 \pm 9,383$ & $66,000 \pm 6,038$ & $68,074 \pm 9,806$ & 1,442/0,243a & \\
\hline Sağ M & $56,667 \pm 8,553$ & $55,778 \pm 6,886$ & $55,148 \pm 9,239$ & 0,229/0,796a & \\
\hline Sağ PM & $64,926 \pm 14,655$ & $62,481 \pm 10,305$ & $60,593 \pm 13,965$ & $0,741 / 0,480 \mathrm{a}$ & \\
\hline Sağ P & $73,852 \pm 14,738$ & $67,074 \pm 12,329$ & $68,000 \pm 14,645$ & 1,874/0,160a & \\
\hline Sağ PL & $74,481 \pm 13,990$ & $70,926 \pm 9,750$ & $70,704 \pm 16,110$ & $0,661 / 0,519 a$ & \\
\hline Sağ L & $77,852 \pm 13,933$ & $72,148 \pm 9,339$ & $74,148 \pm 13,609$ & $1,454 / 0,240 \mathrm{a}$ & \\
\hline Sağ AL & $79,926 \pm 12,779$ & $73,741 \pm 10,090$ & $77,111 \pm 12,217$ & $1,875 / 0,160 \mathrm{a}$ & \\
\hline Sol A & $76,667 \pm 9,911$ & $73,593 \pm 10,562$ & $75,519 \pm 10,980$ & $0,592 / 0,556 a$ & \\
\hline Sol AM & $71,815 \pm 10,684$ & $69,037 \pm 9,681$ & $69,000 \pm 9,572$ & $0,705 / 0,497 a$ & \\
\hline Sol M & $58,074 \pm 8,185$ & $58,926 \pm 7,927$ & $57,704 \pm 10,276$ & $0,135 / 0,874 a$ & \\
\hline Sol PM & $69,000 \pm 15,015$ & $62,370 \pm 13,599$ & $62,889 \pm 13,938$ & $1,821 / 0,169 a$ & \\
\hline Sol P & $78,000 \pm 18,013$ & $68,296 \pm 13,067$ & $68,185 \pm 15,940$ & $3,432 / 0,037 a^{*}$ & $1>2,1>3$ \\
\hline Sol PL & $77,185 \pm 12,878$ & $71,185 \pm 12,285$ & $72,259 \pm 14,740$ & 1,553/0,218a & \\
\hline Sol L & $78,741 \pm 16,924$ & $71,000 \pm 10,745$ & $73,852 \pm 15,769$ & $1,908 / 0,155 a$ & \\
\hline Sol AL & $81,778 \pm 16,263$ & $75,407 \pm 8,993$ & $76,259 \pm 13,963$ & 1,793/0,173a & \\
\hline
\end{tabular}

a, ANOVA testi; *, $p<0,05 ;{ }^{* *}, p<0,001$; SS, standart sapma; Ort, ortalama; A, anterior; AM, anteromedial; M, medial; PM, posteromedial; PL, posterolateral; L, lateral; AL, anterolateral.

Tablo 5. Grupların hamstring ve gastrokinemius kas esneklik değerlerinin ortalamaları

\begin{tabular}{lccccc} 
& Normal Ark & Yüksek Ark & Düşük Ark & & \\
\hline Ort \pm SS & Ort \pm SS & Ort \pm SS & F/p & Fark \\
\hline Gastrokinemius & $34,222 \pm 7,688$ & $38,852 \pm 7,564$ & $34,333 \pm 9,153$ & $2,825 / 0,065 a$ & \\
Hamstring & $2,37 \pm 9,115$ & $-3,926 \pm 11,582$ & $-6,222 \pm 12,562$ & $4,275 / 0,017 a^{*}$ & $1>2,1>3$ \\
\hline
\end{tabular}

a, ANOVA testi; *, $p<0,05 ;{ }^{* \star}, p<0,001$; SS, standart sapma; Ort, ortalama. 
aralığında adölesan grup kadınlarda yapılmıştır. Biodex Balance System tarafından dinamik denge değerlendirmeleri farklı stabilite seviyelerinde mediolateral, anteroposterior ve tüm yönlerde değerlendirilmiş ve normal ayak arkına göre postural stabilitenin azalmış olduğunu bildirilmiştir (2).

Cote ve ark. ayağın deformitelerle ilişkili pronasyon ve supinasyon pozisyonda duruşunun nötral pozisyona göre denge üzerindeki etkilerini incelemiştir. Dinamik denge değerlendirmesinde pronasyon pozisyondaki ayakların nötrale kıyasla anterior ve anteromedial yönde, supinasyon pozisyondakilerin ise posterior ve posterolateral yönde uzanma miktarlarının daha fazla olduğu gösterilmiştir. Bu durum pronasyon duruşta medial kısma, supinasyon duruşta ise lateral kısma artan basınçla ilişkilendirilmiştir (3).

Çalışmamızda dinamik denge posterior değerlendirme sonuçları ayakta görülen ark deformitesinin kişilerin dinamik dengelerini olumsuz etkilediği fikrini desteklemektedir. Cote ve ark.'nın aksine, normal gruba kıyasla medial ve lateral yönlerde anlamlı farklılık olmamasının sebebi çaıışmamızdaki katılımcıların deformitelerinin şiddetlerinin değerlendirilmemesi ile açıklanabilir. Katılımcıların değerlendirme esnasında gövdelerini fleksiyona alarak daha fazla uzanmaya çalışması ve katılımcıların bacak boyunun uzunluğu posteriora uzanma miktarlarının fazla olması ile ilişkilendirilebilir.

Kim ve ark. PP ve nötral durumdaki ayakların statik ve dinamik stabilitelerinin farklılıklarını inceledikleri çalışmalarında, PP ve nötral ayak değerlendirmeleri için iki grup oluşturmuşlardır. Katıımcıları gözler açık ve kapalı tek ayak üstünde durma testi ve $Y$ testi ile değerlendirmişlerdir. Çalışmanın sonucunda nötral grubun statik stabilitelerinin PP grubuna oranla anlamlı yüksek olduğu bildirilmiştir (12).

Kızılcı ve ark. PP'nin erkeklerde fiziksel uygunluk parametrelerine etkisini değerlendirdikleri çalışmada statik denge değerlendirmesinde, PP'nin biyomekanik bozukluklara bağlı olarak dengede kalma süresini azalttığını bildirmiştir. Çalışma 18-45 yaş aralığında yapılmış ve ayak ark durumu Feiss çizgisi esas alınarak değerlendirilmiştir (1).

Çalışmamızda statik denge sonuçları incelendiğinde, gözler açık ve gözler kapalı tek ayak üzerinde durma testinde üç grup arasında anlamlı fark bulunmadı. İki çalışmadaki sonuç farkııı̆ının sebebi, Kızılcı ve ark. çalışmasının 18-45 yaş aralığında, erkek bireylerde ve Feiss çizgisine göre 2. derece PP'ye sahip katılımcılarla yapılmış olmasından kaynaklanabilir. Ark düşüklüğü ve yüksekliğinin karşılaştırılması hedeflenen çalışmamızda ise ark değerlendirmesi yapılırken deformite şiddeti dikkate alınmadı (1).

Kızılcı ve ark. çalışmasında PP'nin şiddetinin artışı ve kalkaneal valgus ile ilişkili olarak, aşil tendonunun laterale kaydığını ve bu durumunun gastrokinemius kasında kısalmayla sonuçlandığını bildirmiştir. PK'da da kalkaneusta görülen mediale açılanma sebebiyle gastrokinemius kasında kısalık görülebildiği rapor edilmiştir (1).

Çalışmamızda normal, düşük ve yüksek ark grupları gastrokinemius kas esneklikleri arasında anlamlı farklılık görülmedi. Bunun sebebi katılımcıların kalkaneus durumunun ve deformite şiddetinin değerlendirilmemesi olabilir. Gruplar arası hamstring kas esnekliği değerlendirildiğinde ise normal arka sahip katılımcıların hamstring kaslarının daha esnek olduğu görüldü. Çalışmada postür analizi yapılmadı ancak literatürde ayak ark değişiminin postürü etkilediğini bildiren yayınlar bulunmaktadır. Bu sebeple pelvisin anterior veya posterior tiltine bağlı olarak hamstring kas esnekliğinin ark etkilenimi olan gruplarda azalmış olduğu düşünülebilir.

Artan BKI, dizin biyomekaniğini olumsuz etkilemekte ve alt ekstremite dizilimi sebebiyle düşük arkla ilişkilendirilmektedir. Tenenbaum ve ark. adölesan bireylerde BKi'de görülen artışın esnek PP ile ilişkili olduğunu bildirmiştir. PP ile BKI ilişkisini inceleyen bir diğer çalışmada ise, BKI artışının lordozda artışa sebebiyet verdiği, bu durumun yerçekimi hattını etkilediği ve ayağa artan yükleme sebebiyle PP'ye sebep olduğu rapor edilmiştir $(13,14)$.

Yaptığımız çalışmada da düşük ark grubunda BKi ortalamasının diğer gruplara oranla yüksek olduğu görüldü. Literatürü destekler şekilde dizde yük artışının tibia vasıtasıyla talusu etkilediği ve ayak arkının yüksekliğinin azalmasına sebep olduğu düşünülebilir.

Yorgunluğun kas iğciği aktivitesinde azalma, afferent duyu kaybı ve pozisyon hissinde azalma, kas ve eklem reseptörlerinin olumsuz etkilenimi sebebiyle dengeyi olumsuz etkilediği bilidirilmiştir. Literatürde yorgunluğun dengeyle ilişkisine yönelik birçok çalışma bulunmaktadır. Bu çalışmaların bazılarında etkilenim görülmezken, bazılarında dengenin yorgunluktan olumsuz etkilendiği belirtilmiştir. Yaşıı bireylerde gastrokinemius kas yorgunluğunun 
dengeye etkisinin incelendiği bir çalışmada yorgunlukta artışın mediolateral stabiliteyi ve tek ayak üstünde durma testini olumsuz etkilediği bildirilmiştir (15-18).

Kalf kaslarının yorgunluğuna bağlı postural salınımın değerlendirildiği bir başka çalışmada da kas yorgunluğunun güç üretme kapasitesinde azalma olarak tanımlandığı ve hem periferik proprioseptif sistemi hem de propriosepsiyonun üst merkezlerinin etkilendiği rapor edilmiştir. Nordane ve ark. yorgunluğun kişilerin vücut dengeleri üzerine etkilerini değerlendirmiştir. Treadmill ve bisiklet ergometresi ile yapılan egzersizler sonrası katılımcıların

\section{Kaynaklar}

1. Kızılcı H, Erbahçeci F. Pes Planus Olan ve Olmayan Erkeklerde Fiziksel Uygunluğun Değerlendirilmesi. Türk Fizyoterapi ve Rehabilitasyon Derg 2016;27:25-33. https://dergipark.org.tr/tr/download/ article-file/253244

2. El-Shamy FF, Ghait AS. Effect of Flexible Pes Planus on Postural Stability in Adolescent Females. Int J Sci Res 2014;3:653-6. https:// pdfs.semanticscholar.org/1391/6e393e13e7d6031e3f49b09fb38fcc bbab5b.pdf

3. Cote KP, Brunet ME, Gansneder BM, Shultz SJ. Effects of pronated and supinated foot postures on static and dynamic postural stability. J Athl Train 2005;40:41-6. https://www.ncbi.nlm.nih.gov/ pmc/articles/PMC1088344/

4. Güven E, Özgün Ali K, Güner S, Altınkaynak H, Alsancak S. Sağlık Hizmetleri Meslek Yüksekokulu Öğrencilerinde Ayak Ark Patolojileri Ile Ayakkabı Tercihleri Arasındaki İlişkinin Değerlendirilmesi. Ankara Sağlık Hizmetleri Derg 2017;16:43-50. https://dergipark.org.tr/tr/ download/article-file/571908

5. Ceyhan Ç, Sanalan GB, Akkaya N, Şahin F. Tıp Fakültesi öğrencilerinde pes planus ve aksiyel ağrı arasındaki ilişkinin değerlendirilmesi. Pamukkale Tıp Derg 2017;10:158-64. [CrossRef]

6. Riccio I, Gimigliano F, Gimigliano R, Porpora G, Iolascon G. Rehabilitative treatment in flexible flatfoot: a perspective cohort study. Chir Organi Mov 2009;93:101-7. [CrossRef]

7. Staheli LT, Chew DE, Corbett M. The longitudinal arch. A survey of eight hundred and eighty-two feet in normal children and adults. J Bone Joint Surg Am 1987;69:426-8. [CrossRef]

8. Springer BA, Marin R, Cyhan T, Roberts H, Gill NW. Normative Values for the Unipedal Stance Test with Eyes Open and Closed. J Geriatr Phys Ther 2007;30:8-15. [CrossRef] dinamik bir denge platfromu üzerinde gözler açık ve kapalı olarak vücut salınımlarını inceledikleri çalışmasında, vücut salınımının yorucu fiziksel aktivite sonrasında arttığı bildirilmiştir. Anaerobik eşik altında yapılan egzersizlerde etkilenimin az olduğu ve ciddi bir etkilenim oluşturmadığı rapor edilmiştir (15-18).

Çalışmamızda tüm değerlendirmeler art arda yapıldığından değerlenme sonuçları etkilenmiş olabilir. Değerlendirmeler çok uzun sürmemekle birlikte yorgunluğun dengeye etkisi çalışmada göz önüne tutulmadı. Bu durumun çalışmamızın eksik yanı olduğunu söyleyebiliriz.

9. Gribble PA, Hertel J, Plisky P. Using the Star Excursion Balance Test to assess dynamic postural-control deficits and outcomes in lower extremity injury: a literature and systematic review. J Athl Train 2012;47:339-57. [CrossRef]

10. Mahajan A. Use of star excursion balance test in assessing dynamic proprioception following anterior cruciate ligament injury. Int J Orthop Sci 2017;3:1-5. [CrossRef]

11. Otman AS, Köse N. Tedavi Hareketlerinde Temel Değerlendirme Prensipleri. Ankara: Hipokrat Kitabevi; 2016. s.48.

12. Kim JA, Lim OB, Yi CH. Differences in static and dynamic stability between flexible flatfeet and neutral feet. Gait Posture 2014;41:54650. [CrossRef]

13. Tenenbaum S, Hershkovich O, Gordon B, Bruck N, Thein R, Derazne E, et al. Flexible Pes Planus in Adolescents. Foot Ankle Int 2013;34:8117. [CrossRef]

14. Chougala A, Phanse V, Khanna E, Panda S. Screening of Body Mass Index and Functional Flatfoot in Adult: An Observational Study. Int J Physiother Res 2015;3:1037-41. [CrossRef]

15. Simoneau $M$, Bégin $F$, Teasdale $N$. The effects of moderate fatigue on dynamic balance control and attentional demands. J Neuroengineering Rehabil 2016;3:22. [CrossRef]

16. Nam HS, Park DS, Kim DH, Kang HJ, Lee DH, Lee $\mathrm{SH}$, et al. The Relationship Between Muscle Fatigue and Balance in the Elderly. Ann Rehabil Med 2013;37:389-95. [CrossRef]

17. Nordane A, Tarantla J, Giordano A, Schieppati M. Fatigue effects on body balance. Electroencephalogr Clin Neurophysiol 1997;105:309_ 20. [CrossRef]

18. Springer B, Pincivero D. The effects of localized muscle and wholebody fatigue on single-leg balance between healthy men and women. Gait Posture 2009;30:50-4. [CrossRef] 